\title{
The impact of neck lymph node volumetric status on local control of the primary tumour (LTC) in radiotherapy for oral cavity and oropharyngeal cancer
}

\author{
Marcin Miszczyk', Bogusław Maciejewski², Magdalena Markowska² \\ ${ }^{1}$ Dept. Radiotherapy \\ ${ }^{2}$ Div. Research Programmes, M. Sklodowska-Curie National Research Institute of Oncology, Gliwice Branch, Poland
}

The study analyses the impact of volumetric nodal involvement (total nodal volume - TNV) on local control of the primary tumour (LTC) in radiotherapy for oral cavity and oropharyngeal cancer. The results show a significant decrease of the LTC (within a constant GTV) by about 10-20\%, when the TNV increases from 10 to $40 \mathrm{~cm}^{3}$. It suggests delivering an extra boost dose of 3-4 extra fractions of $2.0 \mathrm{~Gy}$ fractions to the primary tumour in the case of nodal involvement (initial total nodal volume).

Key words: total nodal volume, local tumour control, extra boost dose

\section{Introduction}

Standard radiotherapy protocols for head and neck cancers define techniques and dose fractionation regimens for primary tumours and for regional neck lymph nodes when they are involved or not. Both depend on tumour (T) or neck nodes (N) stages defined by the TNM staging system. It sounds illogica to use the TNM staging to design technique and dose fractionation, because the direct target for radiation is tumour or nodal volumes (which reflect the initial number of stem cells which have to be eradicated), but not the T and/or N stage. This argument is supported by increasing number of published studies [1-8]

There is no doubt that malignant tumours are highly heterogeneous as regarding their biological characteristics and response to radiotherapy. The ability of a cancer to metastasize to regional lymph nodes is one of its universal characteristics. This does not mean, however, that cancer cells which escape to regional lymph nodes are the same as those which remain in the primary tumour. It is probable that the biology and sensitivity of primary cancer stem cells which remain in the tumour do not necessarily stay unchanged. Therefore, it is interesting to answer to the question whether there is any impact of the involved neck lymph nodes on radiation response (local tumour control - LTC) of the primary tumours compared with those with NO status.

\section{Material and methods}

The retrospective study consists of consecutive 103 patients with oropharyngeal or oral cavity cancer (OPC) treated with radiotherapy alone (3D-IMRT) in a single institution. Based on frequent, serial CT/MRI scans, volumes of primary tumours and neck lymph nodes were estimated using the formula:

$V=4 / 3 \pi r^{3}=4.186 \times r^{3}$ (radias)

\section{How to cite:}

Miszczyk M, Maciejewski B, Markowska M. The impact of neck lymph node volumetric status on local control of the primary tumour (LTC) in radiotherapy for oral cavity and oropharyngeal cancer. NOWOTWORY J Oncol 2021; 71: 74-78.

This article is available in open access under Creative Common Attribution-Non-Commercial-No Derivatives 4.0 International (CC BY-NC-ND 4.0) license, allowing to download articles and share them with others as long as they credit the authors and the publisher, but without permission to change them in any way or use them commercially. 
Volumes of individual lymph nodes were added giving total nodal volume (TNV):

$\mathrm{TNV}=\Sigma_{\mathrm{i}} \mathrm{VN}_{\mathrm{i}}$

The distribution of TNM tumour stages, primary tumour volumes (GTV) and nodal volumes (TNV) is presented in table I. Involved neck nodes $(\mathrm{N}+)$ occurred in 62 patients (60\%) and this group was used to analyze the impact of the TNV on 3-year local control of the primary tumour (LTC). The remaining group of 41 cases withstatus was used as a control group.

Three different $\mathrm{NO}$ dose fractionation regimens were used including conventional treatment with 66-71 Gy in 42-46 days, accelerated CAIR with 70-72 Gy in 35-40 days and hyperfractionated split-course (CHA-CHA) with $64 \mathrm{~Gy}$ in 28 days. Since total doses (TD), doses per fraction (di) and overall treatment times (OTT) differed, to analyze and compare their clinical

Table I. Characteristics of 103 OPC patients in relation to the TNM and volumetric staging

\begin{tabular}{|c|c|c|c|}
\hline Stage & & No. cases & $\%$ \\
\hline \multicolumn{4}{|l|}{ TNM stage } \\
\hline T1-2N0 & & 27 & $26 \%$ \\
\hline $\mathrm{T} 1-2 \mathrm{~N}+$ & & 13 & $13 \%$ \\
\hline T3-4NO & & 14 & $14 \%$ \\
\hline $\mathrm{T} 3-4 \mathrm{~N}+$ & & 49 & $47 \%$ \\
\hline \multicolumn{4}{|c|}{ volumetric diameter primary tumour (PTV) } \\
\hline$\leq 5 \mathrm{~cm}^{3}$ & $\leq 2 \mathrm{~cm}$ & 10 & $10 \%$ \\
\hline $5.1-14 \mathrm{~cm}^{3}$ & $2-3 \mathrm{~cm}$ & 28 & $27 \%$ \\
\hline $14.1-27 \mathrm{~cm}^{3}$ & $3.1-3.7 \mathrm{~cm}$ & 32 & $31 \%$ \\
\hline $27.1-33 \mathrm{~cm}^{3}$ & $3.8-4 \mathrm{~cm}$ & 7 & $7 \%$ \\
\hline $33.1-47 \mathrm{~cm}^{3}$ & $4.1-4.5 \mathrm{~cm}$ & 16 & $15 \%$ \\
\hline$>47 \mathrm{~cm}^{3}$ & $>4.5 \mathrm{~cm}$ & 10 & $10 \%$ \\
\hline \multicolumn{4}{|c|}{ neck lymph nodes (TNV) } \\
\hline NO & $0 \mathrm{~cm}$ & 41 & $40 \%$ \\
\hline$\leq 5 \mathrm{~cm}^{3}$ & $\leq 2 \mathrm{~cm}$ & 31 & $30 \%$ \\
\hline $5.1-14 \mathrm{~cm}^{3}$ & $2-3 \mathrm{~cm}$ & 17 & $16 \%$ \\
\hline $14.1-17 \mathrm{~cm}^{3}$ & $3-3.3 \mathrm{~cm}$ & 8 & $8 \%$ \\
\hline $17.1-35 \mathrm{~cm}^{3}$ & $3.3->4 \mathrm{~cm}$ & 6 & $6 \%$ \\
\hline
\end{tabular}

efficacy, the biologically equivalent dose (BED) was estimated using the following linear-quadratic formula [9]:

$B_{2.0 / 45}=[T D(d i+a / \beta) /(2.0+a / \beta)]+[-(O T T-45$ days $)$. $0.7 \mathrm{~Gy} / \mathrm{d}]$

which, is a biologically equivalent total dose if given in $2.0 \mathrm{~Gy}$ fractions in the OTT of 45 days $\left(\mathrm{BED}_{2.0 / 45}\right)$ using $\mathrm{a} / \beta=10 \mathrm{~Gy}$. Parameter $0.7 \mathrm{~Gy} / \mathrm{d}$ represents an average daily dose, the biological effect of which is neutralized by accelerated repopulation of cancer cells $[10,11]$. The OTT of 45 days represents an average time factor. If the OTT was shorter/longer than 45 days, then the respective factor of the repopulated dose was added to or deducted from the estimated BED $_{2.0 / 45}$ [3]. Physical parameters and respective $\mathrm{BED}_{2.0 / 45}$ of the three fractionation regimens are presented in the table II.

All cases had at least a 3 years follow-up, and therefore the LTC curves estimated using the Kaplan-Meier method are raw, not actuarial. The statistical significance of the LTC differences was estimated using a t-Student test modified by Yates and $p=0.049$ was accepted as a limit of significance.

\section{Results}

For 103 analyzed patients, overall 3-year Local Tumour Control (LTC) was $78 \%$ and $67 \%$ of Locoregional Control (LCR). The LTC-TNM stage relationships (tab. II a) have shown no significant impact of $\mathrm{N}$ stage on the LTC for T1-2, whereas for T3-4 tumours, neck node involvement $(\mathrm{N}+)$ resulted in lower $\mathrm{LTC}$, compared with $\mathrm{N}_{0}$ data sets, however a significant difference ( $p<0.01$ ) was noted only between T1-2N0 and T3-4N+.

For primary tumour GTV volumes, an increase of their sizes resulted in significant $(p<0.01)$ decrease of the LTC. However, changes in the GTV do not linearly correlate with changes in the total nodal volume (TNV) and any analysis of relationships between four variables, which are: LTC, NTD izoGy ${ }_{2.0 / 45}$, GTV and TNV, and the impact of the TNV on the LTC is not simple and

Table Il. 3-year local control of primary tumour (LTC) depending (a) TNM status, (b) volumetric status

\begin{tabular}{|c|c|c|c|c|c|}
\hline \multirow[t]{2}{*}{ Stage } & & \multicolumn{3}{|c|}{ NTD in izoGy ${ }_{2.0 / 45}$} & \multirow[t]{2}{*}{ Overall } \\
\hline & & $60-65$ & $66-70$ & $\geq 75$ & \\
\hline TNM & (a) & & & & \multirow[b]{2}{*}{$85 \%$} \\
\hline T1-2 & NO & $80 \%$ & \multirow[t]{2}{*}{$90 \%$} & $95 \%$ & \\
\hline $\mathrm{T} 1-2$ & $\mathrm{~N}+$ & $75 \%$ & & $90 \%$ & $85 \%$ \\
\hline Т3-4 & NO & $50 \%$ & $70 \%$ & $80 \%$ & $79 \%$ \\
\hline T3-4 & $\mathrm{N}+$ & $45 \%$ & $50 \%$ & $60 \%$ & $59 \%$ \\
\hline volumetric & (b) & \multicolumn{3}{|c|}{$70 \pm 3$ izoGy $_{2.0}$} & \\
\hline $\mathrm{GTV} \mathrm{cm}^{3}$ & TNV $\mathrm{cm}^{3}$ & & \\
\hline & $<10$ & \multirow{2}{*}{\multicolumn{3}{|c|}{$5 / 5-100 \%$}} & \\
\hline 10 & 10 & \multirow{2}{*}{\multicolumn{3}{|c|}{$7 / 8-88 \%$}} & \\
\hline 20 & $<10$ & \multirow{2}{*}{\multicolumn{3}{|c|}{$\begin{array}{c}5 / 7-71 \% \\
8 / 16-50 \%\end{array}$}} & \\
\hline $30-50$ & $20-40$ & \multirow{2}{*}{\multicolumn{3}{|c|}{$\begin{array}{l}8 / 16-50 \% \\
2 / 6-33 \%\end{array}$}} & \\
\hline $40-60$ & $40-60$ & \multirow{2}{*}{\multicolumn{3}{|c|}{$\begin{array}{l}2 / 6-33 \% \\
1 / 6-17 \%\end{array}$}} & \\
\hline $60-90$ & $50-70$ & & & & \\
\hline & & \multicolumn{3}{|c|}{$p<0.0005$} & \\
\hline
\end{tabular}


precise; it is likely to be a source of uncertain interpretation. For that reason, to enhance the reliability of the achieved results claster (which simply means a bunch of grapes) analysis is based on grouping the data into fairly homogenous sets (at least in one or two parameters e.g. GTV and TNV). The aim of such analysis is to find the interrelationship among the analyzed variables and to determine whether some variables can be grouped together based on their similarities. Therefore LTC-TNV-NTD ${ }_{2.0 / 45}$ - relationships were analyzed in the marked out small subsets of data being fairly homogeneous regarding at least one or two parameters. Four clasters include all together 62 cases irradiated with $\mathrm{NTD}_{2.0 / 45}$ in the range $65-75 \mathrm{izoGy}_{2.0 / 45}$.

Figure 1 shows that primary tumour control (LTC) in relation to primary GTV and TNV cannot be represented by a single LTC curve, but there are series of LTC curves that depend on the relations between the tumour and nodal volumes. In claster $\mathrm{A}$ overall arrange LTC equals $86 \%$ but for GTV $\left(<5 \mathrm{~cm}^{3}\right)$, TNV in the range $5-10 \mathrm{~cm}^{3}$ has no impact on the LTC, but for a bit larger GTV $\left(5-10 \mathrm{~cm}^{3}\right)$, TNV of $>10 \mathrm{~cm}^{3}$ causes a decrease of LTC by about $25 \%$, although this tendency is not significant. For larger GTV $\left(>20 \mathrm{~cm}^{3}\right)$ significant $(p<0.005)$ impact of the increasing TNV to more than $50 \mathrm{~cm}^{3}$ results in significant $(p<0.005)$, decreasing LTC from 65\% (claster B) to 33\% (claster D). In claster D local recurrences of primary tumours predominate. This negative impact of the TNV on primary LTC is shown in table $\| \mathrm{b}$, which includes only cases irradiated with the $\mathrm{NTD}_{2.0 / 45}$ within the narrow range of $70 \pm 3$ izoGy $_{2.0 / 45}$. Increasing TNV from $<10 \mathrm{~cm}^{3}$ to $50-70 \mathrm{~cm}^{3}$ for larger GTV (from $5 \mathrm{~cm}^{3}$ to $90 \mathrm{~cm}^{3}$ ) significantly $(p<0.005$ ) lowers 3-year primary LTC. In the group of NO cases (tab. II a), the LTC only depends on the NTD ${ }_{2.0 / 45}$ value.

Figure 2 shows that the LTC curve for NO cases (solid lines) depends on primary GTV compared with the lower LTC curve which represents the impact of involved neck lymph nodes (dotted lines for TNV $>10 \mathrm{~cm}^{3}$ ). The relationship between three variables LTC, GTV and TNV shown in figure 2 convincingly

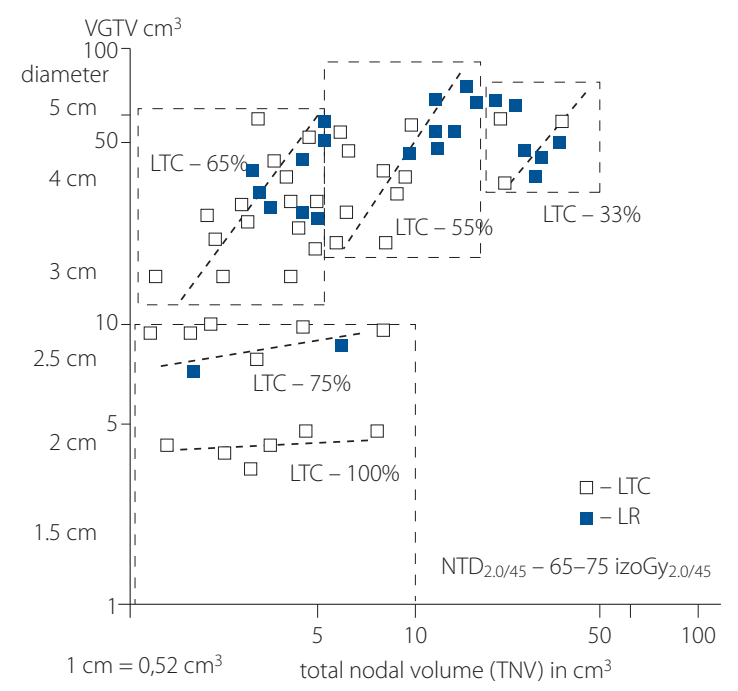

Figure 1. Four data clasters of primary tumour control $(\square)$ or recurrence (-) depending on tumour (GTV) and nodal (TNV) volumes

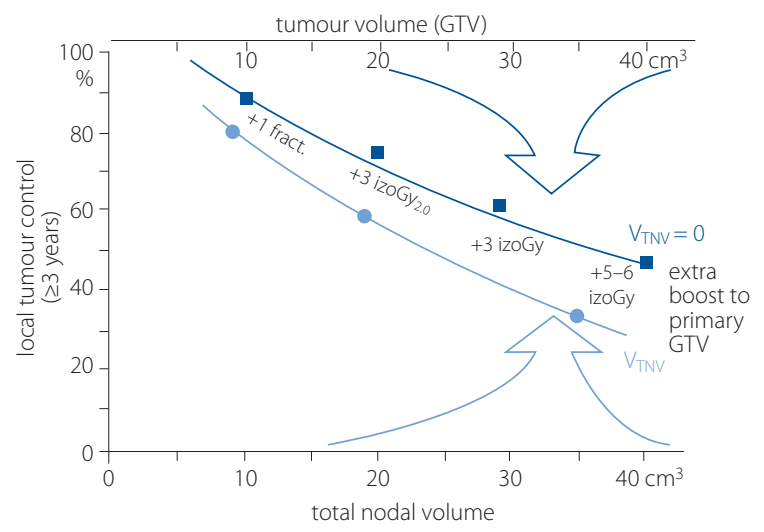

Figure 2. Local tumour control curves for non-involved (匹) and metastatic ( $\bigcirc$ ) neck lymph nodes depending on their total nodal volume (NTV)

confirms the significant negative impact of the total volume of positive neck nodes (TNV) on the lowered LTC, than in the case of the GTVs with no evidence of regional nodal disease; and suggests that in the case of positive TNV, a boost dose of 3-6 izoGy ${ }_{2.0}$ to the primary tumour should be considered to increase the LTC to the level expected for NO status.

\section{Discussion}

For a number of years, growing interest has been focused on the impact of tumour heterogeneities on their response to radiotherapy. A lot of efforts have been focused to identify various types of heterogeneities which may limit tumour radiocurability. Differences in the intrinsic radiosensitivity of tumour cells and environmental factors affecting tumour responses to radiation. Tumour stage and dose fractionation have been considered important parameters to design radiotherapy strategy, including that for head and neck cancers. Primary tumour control (LTC) and neck lymph node curability (RNC) are traditionally considered separately, since techniques and delivered dose fractionation also differ. It is obvious that local control (3- or 5-years) lowers when T and N stage increases (tab. II a).

In the 1980s, some authors [12,13] noted the adverse effect of lymph node involvement on local tumour control, however, for the first time, Wall and Peters et al. [14] demonstrated the direct impact of neck lymph node disease on local control of the primary tumour of the supraglottic larynx (fig. 3). Although authors convincingly documented the negative impact of regional nodal involvement on 5-year local control of the primary laryngeal tumour, this fact was ignored for the next 3-4 decades, until the present study was undertaken. The authors widened $\mathrm{N}$ in TNM staging from 0-3 to 0-9 N scores for the group of 248 patients with supraglottic cancer (149 patients with N0 status). Treatment to the neck varied - only 59 patients (24\%) received whole neck indication, and 38 patients (15\%) had a neck dissection prior to radiotherapy. Moreover, the average total dose (Gy) delivered to the primary tumour was not modified by $\mathrm{N}$ stage, and did not differ much, being in the 


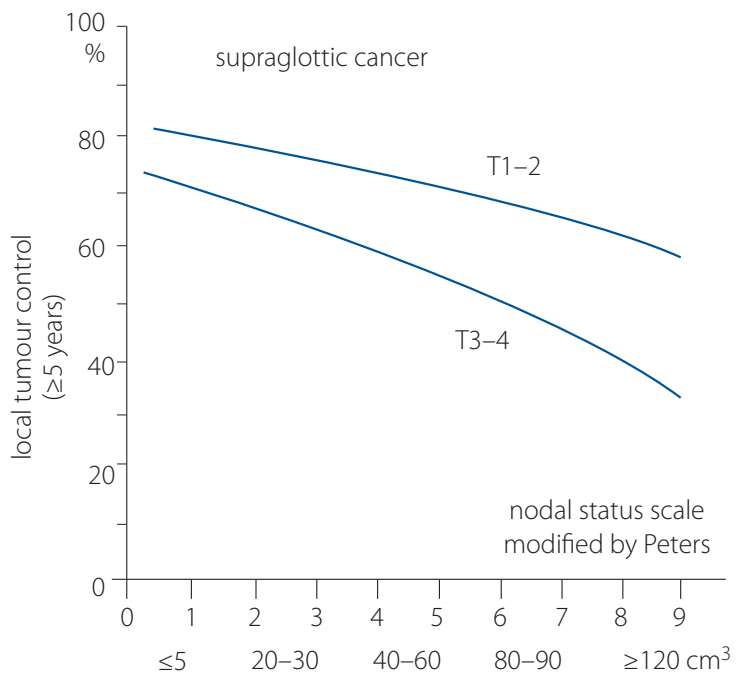

approximate total nodal volume from Wall and Peters study [14]

Figure 3. Wall and Peters [14] local control of T1-2 and T3-4 supraglottic cancer depending on neck lymph node scale (0-9) of metastatic involvement

range of $65 \pm 10 \mathrm{~Gy}$. Despite of that, Wall and Peters clearly showed a significant $(p<0.03)$ decrease of 5 -year TCP of T1-2 and T3-4 with increasing $\mathrm{N}$ scores from 1-9 compared with N0 status (fig. 3). The results of these authors are very similar to those found in the present study (fig. 2). As opposed to their study, in the present one, $T$ and $N$ scores are replaced by more precise parameters as GTV and TNV volumes. Despite the different tumour types, both studies show the same adverse impact of neck node disease on the TCP of the head and neck primary tumour.

According to Wall and Peters, a plausible explanation for such adverse impact of nodal involvement on the primary tumour TCP could be that both primary tumour radioresistance and nodal metastatic potential might result from a higher proportion of clonogenic cancers cells. More jaunly, well oxygenated clonogens escaping into the lymphatics are able to establish metastatic lesions in the regional lymph nodes. The cells which remain to stay in the primary tumour may likely be characterized by slower cell turnover. It is hard to dismiss the possibility that they are synchronized in the most resistant phase of the cell cycle, being even more resistant than hypoxic cells in the more sensitive phase. This does not exclude the other option that the greater the number of clonogenic cells in the tumour and involved population of nodes, the lower the probability that they will be sterilized by a given dose of radiation. Such a concept was defined by Peters et al. [15] as "probabilistic radioresistance". On the other hand, cellular genetic factors may determine primary radioresistance and metastatic potential. Increasing cellular aneuploidy could likely be considered as one such factor. High ploidy H\&N tumours has been recognized as more resistant [16]. Finally Wall and Peters et al. [14] suggest that primary tumour radioresistance was due to inherent cellular characteristics, reflected by nodal metastases. Wall and Peters [15] used a very similar range of delivered doses independent of early or advanced T and N stages. Similarly to the present study, the NTD $2.0 / 45$ for various clasters of the GTV and TNV did not differ very much. Both studies clearly show that a given T stage or GTV volume is not represented by a single dose and the same TCP values, but its differ depending on $\mathrm{N}$ status (N0-9) or in our study, by the TNV volume $\left(0->40 \mathrm{~cm}^{3}\right)$.

\section{Conclusions}

Whatever the mechanism of such an effect is, both studies suggest that primary tumours in patients with nodal involvement should likely be treated more aggressively than those with the same T (or GTV), but without nodal involvement. According to the present results, in the $\mathrm{N}+$ patients, primary tumours should receive an extra boost dose depending on initial GTV and TNV. For the GTV and TNV of about $10 \mathrm{~cm}^{3}$ (early stage), one extra fraction of $2 \mathrm{~Gy}$ is recommended which should increase to 2-3 fractions (each of 2 izoGy $_{2.0 / 45}$ ) with increases in GTV and TNV above $40 \mathrm{~cm}^{3}$.

Conflict of interest: none declared

\section{Bogusław Maciejewski}

M. Sklodowska-Curie National Research Institute of Oncology Gliwice Branch

Div. Research Programmes

Wybrzeże Armii Krajowej 15

44-102 Gliwice, Poland

e-mail:boguslaw.maciejewski@io.gliwice.pl

Received and accepted: 6 Oct 2020

\section{References}

1. Brenner DJ. Dose, volume, and tumor-control predictions in radiotherapy. Int J Radiat Oncol Biol Phys. 1993; 26(1): 171-179, doi: 10.1016/03603016(93)90189-3, indexed in Pubmed: 8482624.

2. Peters LJ, Wendt CD. Tumor volume as a predictor of radiocurability--a drop in the bucket? Int J Radiat Oncol Biol Phys. 1990; 19(2): 497-498, doi: 10.1016/0360-3016(90)90565-2, indexed in Pubmed: 2394628.

3. Mukherji SK, Schmalfuss IM, Castelijns J, et al. Clinical applications of tumor volume measurements for predicting outcome in patients with squamous cell carcinoma of the upper aerodigestive tract. AJNR Am J Neuroradiol. 2004; 25(8): 1425-1432, indexed in Pubmed: 15466346.

4. Plataniotis GA, Theofanopoulou ME, Kalogera-Fountzila A, et al. Prognostic impact of tumor volumetry in patients with locally advanced head-and-neck carcinoma (non-nasopharyngeal) treated by radiotherapy alone or combined radiochemotherapy in a randomized trial. Int J Radiat Oncol Biol Phys. 2004; 59(4): 1018-1026, doi: 10.1016/j. ijrobp.2004.01.021, indexed in Pubmed: 15234035.

5. Studer G, Lütolf UM, El-Bassiouni M, et al. Volumetric staging (VS) is superior to TNM and AJCC staging in predicting outcome of head and neck cancer treated with IMRT. Acta Oncol. 2007; 46(3): 386-394, doi: 10.1080/02841860600815407, indexed in Pubmed: 17450476.

6. Been MJ, Watkins J, Manz RM, et al. Tumor volume as a prognostic factor in oropharyngeal squamous cell carcinoma treated with primary radiotherapy. Laryngoscope. 2008; 118(8): 1377-1382, doi: 10.1097/ MLG.0b013e318172c82c, indexed in Pubmed: 18418275.

7. Knegjens JL, Hauptmann M, Pameijer FA, et al. Tumor volume as prognostic factor in chemoradiation for advanced head and neck cancer. 
Head Neck. 2011; 33(3): 375-382, doi: 10.1002/hed.21459, indexed in Pubmed: 20629076.

8. Studer G, RordorfT, Glanzmann C. Impact of tumor volume and systemic therapy on outcome in patients undergoing IMRT for large volume head neck cancer. Radiat Oncol. 2011; 6: 120, doi: 10.1186/1748-717X-6-120, indexed in Pubmed: 21936952

9. Fowler JF. Practical Time-Dose evaluation, or how to stop working and learn to love Linear Quadratics. In: Lewitt S, Purdy J, Perez C, Poortmans p. ed. Technical Basis of radiation therapy. Practical clinical applications. Heidelberg Springer, Berlin 2012: 3-31.

10. $\mathrm{Mc} \mathrm{Br}$, Withers HR. Biological basis of radiation therapy. In: Perez and Brady's Principle and Practice of Radiation Oncology, 5th ed. Lippincott, Williams and Williams, Philadelphia 208: 78-108.

11. Maciejewski B, Withers HR, Taylor JM, et al. Dose fractionation and regeneration in radiotherapy for cancer of the oral cavity and oropharynx: tumor dose-response and repopulation. Int J Radiat Oncol Biol Phys. 1989; 16(3): 831-843, doi: 10.1016/0360-3016(89)90503-8, indexed in Pubmed: 2921175
12. Harwood AR, Beale FA, Cummings BJ, et al. Supraglottic laryngeal carcinoma: an analysis of dose-time-volume factors in 410 patients. Int J Radiat Oncol Biol Phys. 1983; 9(3): 311-319, doi: 10.1016/03603016(83)90289-4, indexed in Pubmed: 6404867.

13. Van de, Ostoya F. van der Schueren E. The different clinical presentation behavior and prognostic of carcinomas originating in the epilarynx and the lower supraglottis. Radiother Oncol. 1983; 1: 117-131.

14. Wall TJ, Peters LJ, Brown BW, et al. Relationship between lymph nodal status and primary tumor control probability in tumors of the supraglottic larynx. Int J Radiat Oncol Biol Phys. 1985; 11(11): 1895-1902, doi: 10.1016/0360-3016(85)90269-x, indexed in Pubmed: 4055449.

15. Peters LJ, Withers HR, Thames HD, et al. Tumor radioresistance in clinical radiotherapy. Int J Radiat Oncol Biol Phys. 1982; 8(1): 101-108, doi: 10.1016/0360-3016(82)90392-3, indexed in Pubmed: 7061244.

16. Holm LE. Cellular DNA amounts of squamous cell carcinomas of the head and neck region in relation to prognosis. Laryngoscope. 1982; 92(9 Pt 1): 1064-1069, indexed in Pubmed: 7121161. 